\title{
Ecofriendly Treatment of Azo Dyes: Biodecolorization using Bacterial Strains
}

\author{
A.Tripathi, S.K. Srivastava
}

\begin{abstract}
In the present study an attempt was made to examine the potential of different bacterial strains for decolorization of Acid Orange 10, (azo dye) in batch reactors. The effect of media condition, $\mathrm{pH}$, temperature and initial concentration of dye was studied with an aim to determine the optimal conditions required for maximum decolorization and degradation. The bacterial strains used in the study were Pseudomonas putida, Bacillus cereus, Pseudomonas fluorescens, Bacillus subtilis, Alcaligens sp. and Staphylococcus aureus. Out of these Pseudomonas putida emerged out to be most potent decolorizer, being selected for further studies. The selected bacterium shows higher decolorization in static condition as compared to shaking condition. The optimum pH for decolorization of Acid Orange 10 by Pseudomonas putida was 7.0. It shows good decolorization efficiency even in alkaline region. The optimum temperature was $37^{\circ} \mathrm{C}$. The strain could decolorize Acid Orange $10(250 \mathrm{mg} / \mathrm{l})$ by $90 \%$ within $24 \mathrm{~h}$ under the optimum conditions of static condition, $\mathrm{pH}$ 7.0, temperature of $37^{\circ} \mathrm{C}$ and initial dye concentration of $250 \mathrm{mg} / \mathrm{l}$. The result shows that the selected culture has good potential in removal of Azo dyes from waste water under static conditions.
\end{abstract}

Index Terms-Biodecolorization, Pseudomonas putida, Acid Orange 10, static condition, Azo dye

\section{INTRODUCTION}

Different dyes used in textile industry usually have a synthetic origin and complex aromatic molecular structures which make them more stable and more difficult to be biodegraded. Due to their ease of manufacturing methodology, azo dye accounts for almost $80 \%$ of annual production of commercial dyes all over the world. There are over 10,0000 commercially available dyes with a production of over $7 \times 10^{5}$ tons per year [1]. Azo dyes, containing one or more azo bond $(-\mathrm{N}=\mathrm{N}-)$, account for $60-70 \%$ of all textile dyestuffs used [2]. It is estimated that about $10-15 \%$ of the total production of colorants is lost during their synthesis and dyeing Processes [3, 4]. Whereas, in the case of reactive dyes almost $50 \%$ of the initial dye load is found in the dye bath effluents. Colored industrial effluent is the most obvious indicator of water pollution and the discharge of highly colored synthetic dye effluents is aesthetically displeasing and cause considerable damage to the aquatic life. Although several physical-chemical methods have been used to eliminate the colored effluents in wastewater, they are generally expensive, produce large amounts of sludge. More often these conventional modes of treatment lead to the formation of some harmful side products. Interest is

Manuscript received April 7, 2011

School of Biochemical Engineering, Institute of Technology, Banaras Hindu University, Varanasi-221005, India(email address: sksribhu@gmail.com). therefore now focused on the microbial biodegradation of dyes as a better alternative [5]. Some microorganisms, including bacteria, fungi and algae, can degrade or absorb a wide range of dyes [6] .The biological mode of treatment of dye bath effluents offers distinct advantages over the conventional modes of treatment. This method is more economical and leads to less accumulation of relatively harmless sludge. Most importantly, biological treatment of dye bath effluents is ecofriendly. It causes mineralization of dyes to simpler inorganic compounds which are not lethal to life forms. The basic step in the decolorization and degradation of azo dyes is breakdown of azo bonds, leading to removal of color. Azo dyes are known to undergo reductive cleavage whereas the resultant aromatic amines are metabolized under aerobic conditions [7]. So for complete mineralization of azo dyes the microbial population forming part of treatment system should be able to work efficiently under both anaerobic and aerobic conditions. In view of these problems the most potent bacterial culture was selected in this study for maximum decolorization of Acid Orange 10 (azo dye), being selected as model azo dye.

\section{MATERIALS AND METHODS}

\section{A. Microorganism and culture medium}

Pseudomonas putida MTCC 102, Pseudomonas fluorescens MTCC 103 and Bacillus cereus MTCC 3105 were purchased from IMTECH, Chandigarh, India, whereas Bacillus subtilis NCIM 2063, Alcaligens sp. NCIM 5085, Staphylococcus aureus NCIM 2901 were purchased from NCL, Pune, India. Pure cultures were maintained on nutrient agar slants. Composition for nutrient medium used for decolorization studies was $\left(\mathrm{g} \mathrm{l}^{-1}\right)$ Nacl 5, Peptone 10, Beef extract 10.

\section{B. Dyes and Chemicals}

The textile dye Acid Orange 10 was obtained from Himedia, India. All the chemicals were of highest purity available and were of analytical grade.

\section{Experimental methods}

The bacterial cultures were transferred to fresh nutrient medium containing Acid Orange $10(250 \mathrm{mg} / \mathrm{l})$ and were incubated at $32{ }^{\circ} \mathrm{C}$, under static condition for 3 days. After 3 day, aliquots $(5 \mathrm{ml})$ of the culture media were withdrawn, centrifuged at $10,000 \mathrm{~g}$ for 10 minutes in a centrifuge at room temperature to separate the bacterial cell mass. The supernatant was used for analysis of decolorization and all the experiments were repeated in triplicates. Absorbance of the supernatant withdrawn at different time intervals were measured at the Absorbance maximum wavelength for the 
dye Acid Orange $10(\lambda \max =480 \mathrm{~nm})$ in the visible region on a Shimadzu double beam spectrophotometer (UV 1601). The percentage of decolorization was calculated from the difference between initial and final values using the following formula:

\section{$\%$ Decolorization $=$ \\ Initial absorbance value-final absorbance value x100} Initial absorbance value

The bacterial strain giving maximum decolorization values was selected and used for further decolorization experiments. Changes in Chemical Oxygen Demand (COD) and Biological Oxygen Demand (BOD) were also studied using Standard Methods for Examination of Water and Wastewater APHA, 1995.

\section{Conical flask assay}

Conical flask assay was performed for the detection of decolorizing activity of bacteria. The nutrient broth containing Acid Orange 10 was autoclaved at $121{ }^{\circ} \mathrm{C}$ for 15 minutes. $5 \%$ inoculums of the selected culture showing maximum decolorizing activity was added to nutrient broth flasks containing Acid Orange $10\left(250 \mathrm{mg} \mathrm{l}^{-1}\right)$. The flasks were covered with Aluminum foils and were incubated at 32 ${ }^{0} \mathrm{C}$ for 3 days. The flasks were observed for decolorization of the azo dye present in the medium (Fig.2).

\section{E. Optimization of parameters}

In an attempt to study the effect of static and shaking (140 rpm) condition, the selected, most potent decolorizing bacterial culture, was cultivated for $24 \mathrm{~h}$ in nutrient broth and amended separately with $250 \mathrm{mg} / \mathrm{l}$ of Acid Orange 10. To determine the effect of $\mathrm{pH}$ on decolorization, the fully grown culture was inoculated in conical flasks containing $100 \mathrm{ml}$ nutrient broth of varying $\mathrm{pH}$ (4-10) and was amended with $250 \mathrm{mg} / \mathrm{l}$ of Acid Orange 10. The $\mathrm{pH}$ values were adjusted using $1 \mathrm{~N} \mathrm{NaOH}$ and $1 \mathrm{~N} \mathrm{HCl}$. In the similar fashion, the optimum temperature of dye decolorization by selected bacterium was determined by evaluating the dye decolorization at 20,30,37, 40 and $50{ }^{\circ} \mathrm{C}$. After different time intervals, aliquot $(5 \mathrm{ml})$ of the culture media was withdrawn and supernatants obtained after centrifugation was used for analysis of decolorization by Shimadzu double beam spectrophotometer (UV 1601), according to the methods explained earlier.

\section{F. Concentration studies}

The selected culture was cultivated for $24 \mathrm{~h}$ in conical flask containing $100 \mathrm{ml}$ nutrient broth. After $24 \mathrm{~h}$ the media was amended with the dye Acid Orange 10 at a concentration of $100,250,500,750$ and $1000 \mathrm{mg} / 1$ separately to study the effect of increasing dye concentration on percentage dye decolorization.

\section{G. Biodecolorization and biodegradation analysis}

The analysis was done using UV-VIS spectrometry, TLC and FTIR. The supernatants obtained after decolorization were extracted with dichloromethane and dried over anhydrous $\mathrm{Na}_{2} \mathrm{So}_{4}$ and evaporated to dryness. The residue obtained was first examined by Thin Layer Chromatography (TLC). It is further subjected to FTIR spectroscopy. Infrared spectra were determined on Thermo FT-IR spectrophotometer (Nicolet -1700).

\section{RESUlTS AND DISCUSSION}

\section{A. Evaluation of optimum conditions}

The dye decolorization of azo dye Acid Orange 10 was studied under static condition with an initial dye concentration of $250 \mathrm{mg} / \mathrm{l}$ using different bacterial cultures of Pseudomonas putida MTCC 102, Bacillus cereus MTCC 3105, Pseudomonas fluorescens MTCC 103, Bacillus subtilis NCIM 2063, Alcaligens sp. NCIM 2901 and Staphylococcus aureus NCIM 2901. Out of these cultures, Pseudomonas putida MTCC 102 was the best decolorizer with a percentage decolorization value of $90 \%$, followed by Bacillus cereus, Bacillus subtilis and Pseudomonas fluorescens with an efficiency of $65 \%, 54 \%$ and $39 \%$ respectively. The remaining two cultures of Alcaligens $s p$. shows $4 \%$ and staphylococcus aureus show 2\% decolorization (Fig.1). Thus, Pseudomonas putida MTCC 102 was selected for further decolorization experiments, with getting aware of its decolorizing potential. It was observed that under static anoxic conditions, the dye decolorization of Acid Orange 10 was $90 \%$ within $24 \mathrm{~h}$ as compared to $32 \%$ under agitation, respectively (Fig.3a). Hence, Static conditions were preferred to investigate bacterial dye decolorization in further experiments. The result bears similarity with those of studies on Pseudomonas desmolyticum and Pseudomonas luteola. It was found out that under agitation conditions, presence of oxygen deprives the azoreductase from obtaining electrons needed for cleavage of azo dyes. Whereas under static conditions, these electrons are available to azoreductase from NADH to decolorize azo dyes [8],[9]. The optimum $\mathrm{pH}$ for Pseudomonas putida MTCC 102 was pH 7.0. However, Pseudomonas aeruginosa NCIM 102 was also capable of decolorizing the dye over a $\mathrm{pH}$ range of 7-9 with a good efficiency (Fig.3b). Majority of the azo dye reducing bacterial species reported [10], [11] and [12] so far were able to reduce the dye at $\mathrm{pH}$ near 7 . The decolorization of the dye, Acid Orange 10 were studied with temperature range of 20 to $50{ }^{0} \mathrm{C}$. The optimum temperature for Pseudomonas putida MTCC 102 was $37{ }^{\circ} \mathrm{C}$ (Fig.3c). Considerable decrease in Chemical Oxidation Demand (COD) and Biochemical Oxygen Demand (BOD) was also observed. The values for Reduction in COD were $85 \%$ and BOD was $75 \%$ respectively (Fig.4).

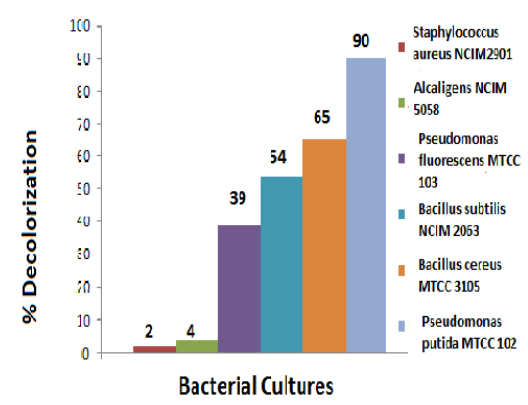

Fig.1 Percentage decolorization of Acid Orange $10(250 \mathrm{mg} / \mathrm{l})$ by different bacterial cultures at $32{ }^{\circ} \mathrm{C}$ at static condition. Pseudomonas putida MTCC 102 is found to be best suitable strain for decolorization of Acid Orange 10. 


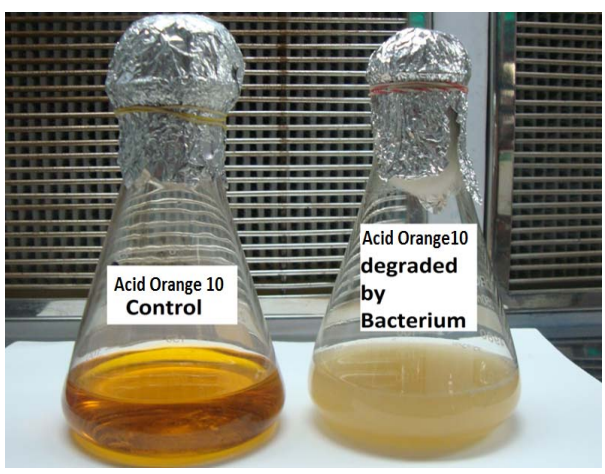

Fig.2. Conical flask assay showing decolorization in the nutrient broth amended with Acid Orange 10 and inoculated with Pseudomonas putida whereas uninoculated (Control) flask retains the color of the azo dye.

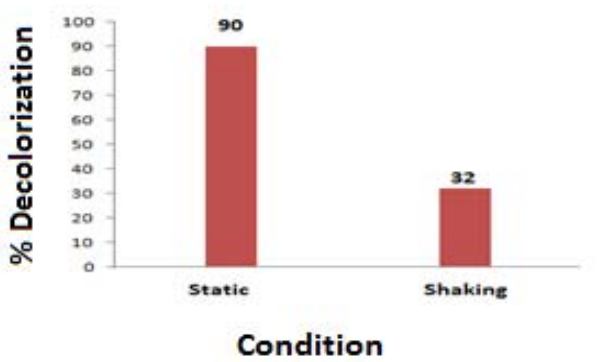

(a)

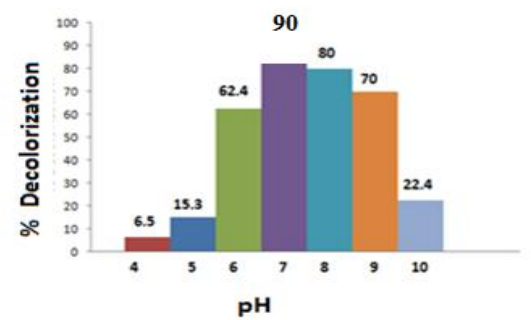

(b)

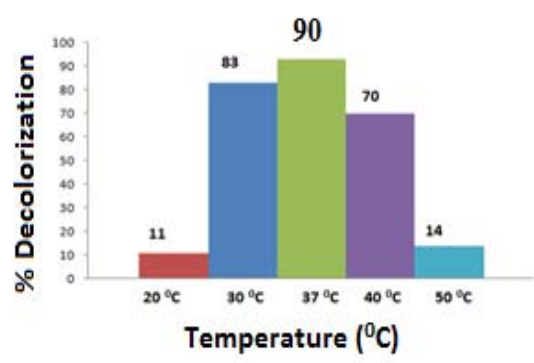

(c)

Fig.3. Effect of (A) Agitation, (B) $\mathrm{pH}$ and (C) Temperature, on the dye decolorization efficiency of Pseudomonas putida MTCC 102 was studied for $24 \mathrm{~h}$ in nutrient medium containing $250 \mathrm{mg} / \mathrm{l}$ dye at $37^{\circ} \mathrm{C}, \mathrm{pH} 7.0$ and under static anoxic conditions, unless specified otherwise.

\section{B. Effect of different concentration of dye on decolorization}

Percentage decolorization of Acid Orange 10 by Pseudomonas putida MTCC 102 was found to vary with initial concentrations $(100-1000 \mathrm{mg} / \mathrm{l})$ when studied up to
48 h. The $90 \%$ decolorization of Acid Orange 10 was observed within 16, 20 and $36 \mathrm{~h}$ for the dye concentration of 100,250 and $500 \mathrm{mg} / \mathrm{l}$, respectively at optimum conditions of $\mathrm{pH} 7.0$, temperature $37{ }^{\circ} \mathrm{C}$ and under static batch study. However, for the dye Acid Orange 10 concentration of 750 $\mathrm{mg} / \mathrm{l}$, maximum decolorization of $65 \%$ and for dye concentration of $1000 \mathrm{mg} / \mathrm{l}$, only $55 \%$ of decolorization was achieved (Fig 5). This is because of the toxic nature of azo dyes. The Percentage decolorization is found to be decreasing with increase in dye concentration as evident from fig.5. The dye decolorizing potential of Pseudomonas putida MTCC 102 was quite high and it decolorizes the dye with better efficiency even at high concentrations of Acid Orange 10. Pseudomonas putida MTCC 102 was able to decolorize the dye at a concentration much higher than other bacterial strains [13], [14], and [15]. The Pseudomonas putida MTCC 102 could tolerate Acid Orange 10 up to $1 \mathrm{~g} / \mathrm{l}$ which is in contrast to the toxic effect reported for the azo dye Acid Orange 10 in concentrations within 0.037-0.051 $\mathrm{mM}$ [16]. This observation is of significance for bioremediation since it indicates potential of Pseudomonas putida MTCC 102 to withstand high concentration of azo dye. Due to its high degrading potential, Pseudomonas putida MTCC 102 could be used successfully in treatment of textile waste waters as they contain high concentration of azo dyes.

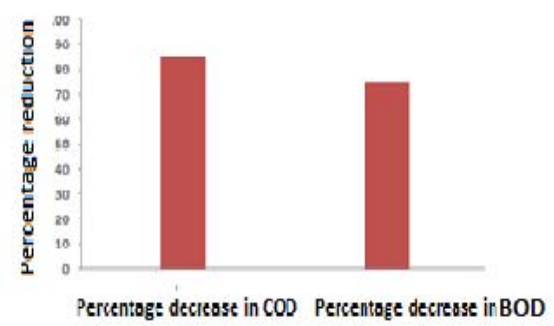

Fig.4 Percentage reduction in COD and BOD values of dye caused by Pseudomonas putida MTCC 102 was studied for $24 \mathrm{~h}$ in nutrient medium containing $250 \mathrm{mg} / 1$ dye at $35^{\circ} \mathrm{C}$, pH 7.0 and under static anoxic conditions, unless specified otherwise.

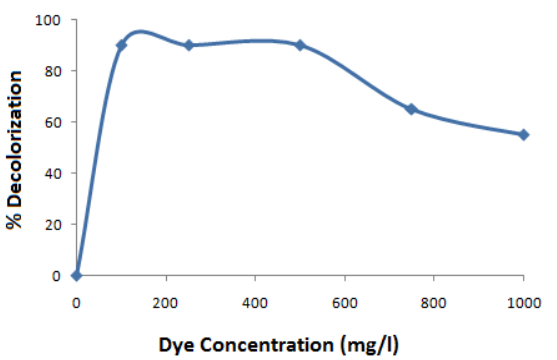

Fig.5. Effect of increasing dye concentration on the Percentage decolorization of Acid Orange 10 by Pseudomonas putida MTCC 102 was studied for $48 \mathrm{~h}$ in nutrient medium containing different dye concentration, at $37{ }^{\circ} \mathrm{C}$ and $\mathrm{pH} 7.0$ and under static conditions.

\section{Identification of metabolic intermediates}

Inoculation of Pseudomonas putida MTCC 102 to media containing azo dyes resulted in the decolorization of the dye, Acid Orange 10. The Biodecolorization was confirmed by 
UV-VIS spectrum. The UV-VIS spectra corresponding to initial and final samples of decolorization experiments as shown in Fig.4. The absorbance analyzed from $300 \mathrm{~nm}$ to $800 \mathrm{~nm}$. The initial dye solution showed high peak at the wavelength of $480 \mathrm{~nm}$. The decolorized sample showed lowering of peak to a minimal absorbance value for dye concentration $250 \mathrm{mg} / \mathrm{l}$, which indicates that the decolorization is due to dye degradation (Fig.6.A). The dye degradation by pseudomonas putida MTCC 102 was further supported by TLC analysis. The spots observed in the initial dye solution was different from the spot observed in the supernatant obtained after decolorization (Fig 6B.).The supernatant obtained after dye decolorization was different from the original dye which was suggested by different $R f$ values. This clearly indicates that decolorization was due to degradation of dyes into intermediate products. The initial step in bacterial degradation of dye is reductive cleavage of $\mathrm{N}=\mathrm{N}$ (azo) bond leading to formation of colorless aromatic amines. These amines are further oxidized to simpler forms. FT-IR analysis was done to characterize the metabolite produced. The results of FT-IR analysis of the dye Acid Orange 10 and sample obtained after decolorization showed various peaks. The FT-IR spectra of Acid Orange 10 control dye display peaks at 3535.9, 1634, 1494, 1198.2, 1035.4 . The IR spectra of degradation product display peak for $-\mathrm{OH}$ stretching. The peak characteristic of azo bond at 1494 of Acid Orange 10 was absent in the decolorized sample, indicating degradation of Acid Orange 10 to aromatic amines as intermediate products which are subjected to oxidation giving rise to simpler compounds. During the degradation of aromatic amines of Acid Orange 10, formation of aromatic aldehyde as an intermediate was confirmed by the spot test using 2, 4-dinitro phenyl hydrazine reagent which indicates color test due to presence of aldehyde.

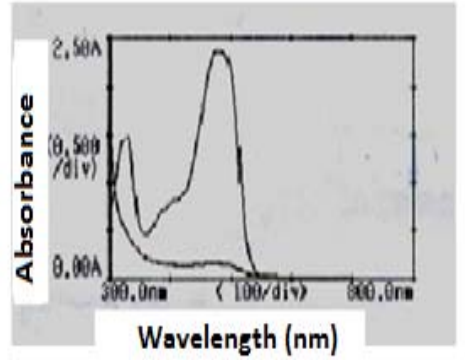

(a)

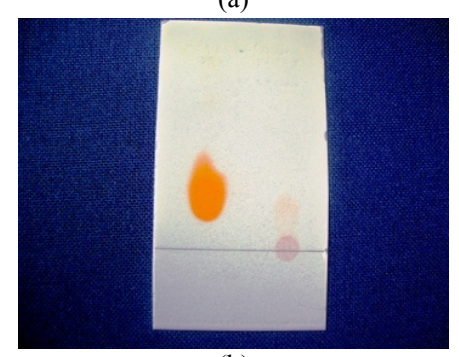

(b)

Fig. 6 (A) UV-Vis Spectrum of Acid Orange 10, before and after decolorization. Lowering of peak at the wavelength maximum (480 $\mathrm{nm}$ ) of clear supernatant indicates azo cleavage by Pseudomonas putida MTCC 102.The spectra indicate a decolorization of about 90\%. (B) TLC experiments shows different Rf values of control dye solution and decolorized samples.

\section{CONCLUSION}

The results, thus, obtained have characterized and identified dye degrading efficiency of pseudomonas putida MTCC102. The ability of the strain to tolerate, decolorize and degrade azo dyes at high concentration gives it an advantage for treatment of textile industry wastewater. However, potential of culture needs to be demonstrated for its application in treatment of real dye bearing wastewaters using appropriate bioreactors.

\section{ACKNOWLEDGEMENTS}

The authors thank UGC for granting research fellowship and laboratory facilities of School of Biochemical Engineering, Institute of Technology, Banaras Hindu University, Varanasi, India.

\section{REFERENCES}

[1] Fu Y, Viraraghavan $\mathrm{T}$ (2001) Fungal decolorization of dye wastewaters: a review. Bioresour. Technol. 79: 251-262.

[2] Carliell CM, Barclay SJ, Naidoo N, Buckley CA, Mulholland DA, Senior E. Microbial decolourisation of a reactive azo dye under anaerobic conditions. Water SA 1995; 21(1):61-9.

[3] Easton J. The dye maker's view. In: Cooper P, editor. Colour in dyehouse effluent. Bradford, UK: Society of Dyers and Colourists; 1995. p. 11.

[4] Maguire RJ. Occurrence and persistence of dyes in a Canadian river. Water Sci Technol 1992; 25:265-70.

[5] An SY, Min SK, Cha IH, Choi YL, Cho YS, Kim CH, Lee YC (2002) Decolorization of triphenylmethane and azo dyes by Citrobacter sp. Biotechnol. Lett. 24: 1037-1040.

[6] Robinson T, McMullan G, Marchant R, Nigam P (2001) Remediation of dyes in textile effluent: a critical review on current treatment technologies with a proposed alternative. Bioresour. Technol. 77: 247-255.

[7] Kapdan IK, Tekol M, Sengul F. Decolorization of simulated textile wastewater in an anaerobic-aerobic sequential treatment system. Proc Biochem 2003; 38:1031-7.

[8] Stolz A .Basic and applied aspects in the microbial degradation of azo dyes. Appl Microbiol Biotechnol, 56 (2001) 69-80.

[9] Chang JS, Kuo TS. Kinetics of bacterial decolorization of azo dyes with Escherichia coli NO3. Bioresour. Technol., 75(2000) 107-111.

[10] Kalme S, Ghodake G, Gowindwar S. Red HE7B degradation using desulfonation by Pseudomonas desmolyticum NCIM 2112. Int Biodeter Biodegr., 60 (2007) 327-333.

[11] Chang JS, Lin CY. Decolorization kinetics of a Recombinant Escheria coli strain harboring azo dye decolorizing determinants from Rhodococcus sp. Biotechnol. Lett., 23 (2001) 631-636.

[12] Suzuki T, Timofei S, Kurunczi L, Dietze U, Schuurmann.Correlation of aerobic biodegradability of Sulfonated azo dyes with the chemical structure. Chemosphere, 45 (2001) 1-9.

[13] Coughlin MF, Kinkle BK, Bishop PL. Degradation of azo dyes containing aminonapthol by Sphignomonas sp strain 1CX. J.Inds.Microbio Biotechnol, 23 (1999) 341-346.

[14] Asad S, Ammozegar MA,Sarbolouki MN, Dastgheib SMM. Biores. Technol, 98 (2007) 2082-2088.

[15] Nachiyaar CV, Rajkumar GS. Degradation of a tannery and textile dye, Navitan Fast Blue S5R by Pseudomonas aeruginosa.W.Journ.Microbiol Biotechnol. , 19 (2003) 609-614.

[16] Sheshadri S, Bishop PL, Agha AM. Anaerobic/aerobic treatment of selected azo dyes in wastewater. Waste manage., 14 (1994) 127-137. 